Volume 7, No. 2, 2021

ISSN (print) : 2442-3217 / ISSN (online) : 2716-3806

Email : mimbarjurnal@gmail.com

Homepage : http://journal.iaimsinjai.ac.id/indeks.php/mimbar

DOI $\quad$ : https://doi.org/10.47435/mimbar.v7i2

\title{
SOLUSI DAKWAH DALAM MENYIKAPI PROBLEMATIKA EKONOMI MASYARAKAT KONTEMPORER
}

\author{
Faridah $^{1}$, Rahmatullah ${ }^{2}$, Muhammad Yusuf $^{3}$ \\ ${ }^{I}$ Institut Agama Islam Muhammadiyah Sinjai, Sinjai \\ ${ }^{2}$ Institut Agama Islam Muhammadiyah Sinjai, Sinjai \\ ${ }^{3}$ Sekolah Tinggi Agama Islam Darud Dakwah Wal Irsyad Makassar, Makassar \\ ${ }^{1}$ Email; andifaridah81@gmail.com \\ ${ }^{2}$ Email: Rahmatbugis1983@gmail.com, \\ ${ }^{3}$ Email: yusufburhan8588@gmail.com
}

\begin{abstract}
This paper describes the solution to da'wah in addressing the economic problems of contemporary society. Da'wah as a means or way in conveying religious teachings should understand the condition of the people, understand the causes of poverty suffered by the people which consists of three factors, namely individual cultural psychological factors, structural factors and inherited or hereditary factors. The problem given is that the problem of poverty requires cooperation from various elements of society using religious, structural, da'wah, psychological, educational, economic and social approaches.
\end{abstract}

Keywords: Da'wah Solutions, Economic Problems, Contemporary Society.

\begin{abstract}
Abstrak
Tulisan ini menguraikan tentang solusi dakwah dalam menyikapi problematika ekonomi masyarakat kontemporer. Dakwah sebagai sarana atau jalan dalam menyampaikan ajaran-ajaran agama sebaiknya memahami tentang kondisi umat, memahami penyebab kemiskinan yang diderita oleh umat yangb terdiri atas tiga faktor yaitu faktor psikologis kultural individu, faktor struktural dan faktor warisan atau keturunan, menyikapi hal tersebut maka solusi dakwah yang diberikan adalah problematika kemiskinan memerlukan kerjasama dari berbagai elemen masyarakat dengan menggunakan pendekatan keagamaan, struktural, dakwah, psikologi, Pendidikan, ekonomi dan sosial.
\end{abstract}

Keyword; Solusi Dakwah, Problematika Ekonomi, Masyarakat Kontemporer.

\section{Pendahuluan}

Problematika ekonomi masyarakat dewasa ini semakin memprihatinkan. Angka kemiskinan dan masyarakat yang kelaparan kembali mengalami peningkatan yakni pada bulan Maret 2021 menjadi 27,54 juta orang, meskipun telah mengalami penurunan di bulan September 2020 dan di bulan maret 2021 telah mencapai angka penurunan hingga 27,54 juta orang (Fauzie, 2021). Namun 


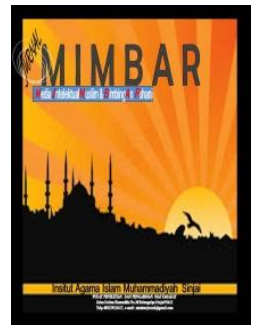

Volume 7, No. 2, 2021

ISSN (print) : 2442-3217 / ISSN (online) : 2716-3806

Email : mimbarjurnal@gmail.com

Homepage : http://journal.iaimsinjai.ac.id/indeks.php/mimbar

DOI : https://doi.org/10.47435/mimbar.v7i2

jumlah tersebut bukanlah angka yang kecil jika dirasionalkan dengan tingkat kepadatan penduduk Indonesia dewasa ini.

Fakta serupa dikabarkan berdasarkan data dari Badan Pusat statistic disampaikan bahwa per Maret 2021 terdapat 27,54 juta orang miskin di Indonesia (Indonesia, 2021). Adapun tingkat kemiskinan dalam skala global menurut Kepala Badan Pangan PBB, David Beasley adalah mencapai angka kisaran 270 juta orang dengan resiko meninggal karena kelaparan sebanyak 30 juta orang (Tim PRMN 03, 2020).

Menyikapi angka kemiskinan dengan resiko meninggal karena kelaparan baik dalam skala global maupun nasional merupakan fakta yang sangat memprihatinkan dan menghawatirkan. Agama yang dianggap sebagai aspek yang memiliki peran strategis terhadap perubahan sosial masyarakat termasuk dalam aspek ekonomi menjadi salah satu sasaran kajian dalam mencari solusi atas problematika umat (Martono, 2012).

Sesungguhnya problematika kemiskinan disebabkan oleh dua faktor yakni faktor internal dan faktor ekternal. Salah satu faktor internal adalah dari sikap berpikir dan keyakinan yang bersumber dari pemahaman agama yang keliru.

Islam sebagai salah satu agama dakwah dalam hal ini tidak luput dari bahan kajian terkait dengan merebaknya angka kemiskinan dan kelaparan. Adanya kesalahpahaman dari segelintir umat pemeluk agama Islam terhadap ayat-ayat al-Qur'an yang memaparkan tentang ketidakberdayaan umat manusia terhadapa keMaha Kuasaan Allah swt, telah menimbulkan sikap pesimis dan apatis terhadap kehidupan dunia dan mereka hanya fokus dalam memikirkan kehidupan akherat. Pemikiran dari faham keislaman mengacu kepada pemikiran Jabariyah. Dampak dari pemikiran Jabariyah telah banyak melahirkan sikap mental umat Islam yang pasrah kepada nasib atau takdir Allah swt. Pola pikir dan sikap umat Islam tentang paham zuhud (hidup sederhana) yang ditanamkan telah menimbulkan sikap kurang menghargai hal-hal yang berbau material (Nadjib, 2013).

Menyikapi problematika umat tersebut, maka salusi dakwah sangat dibutuhkan karena dakwah merupakan denyut nadi Islam, kesalahpahaman umat 


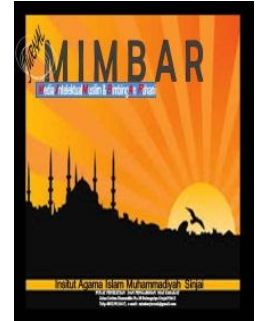

Volume 7, No. 2, 2021

ISSN (print) : 2442-3217 / ISSN (online) : 2716-3806

Email : mimbarjurnal@gmail.com

Homepage : http://journal.iaimsinjai.ac.id/indeks.php/mimbar

DOI : https://doi.org/10.47435/mimbar.v7i2

atas ajaran agama yang dianutnya membutuhkan kerja keras, kerja cerdas, kerja ikhlas dan kerja tuntas dari para aktivis dan organisasi dakwah. Hal ini bertujan agar Islam benar-benar terealisasi sebagai rahmat bagi semesta alam.

Mencermati problematika ekonomi masyarakat yang dikaitkan dengan agama dan peran dakwah seperti yang dijelaskan di atas menginspirasi penulis untuk mengkaji lebih jauh hal tersebut. Menarik untuk menelusuri tentang peran dakwah sebagai jalan untuk menyampaikan ajaran-ajaran Islam dan solusinya dalam menyikapi problematika ekonomi masyarakat. Pada pemaparan berbagai problematika kehidupan pada latar belakang masalah di atas menarik untuk dikaji lebih jauh dengan memfokuskan kajian pada rumusan masalah yaitu bagaimana solusi dakwah dalam menyikapi problematika ekonomi masyarakat.

\section{Metode}

Penelitian ini adalah penelitian kualitatif yakni berupa kajian lapangan dan pustaka yakni melakukan penelusuran tentang solusi dakwah dalam menyikapi problematika ekonomi masyarakat kontemporer. Tulisan ini dikumpulkan dengan menggunakan teknik observasi dan dokumentasi. Peneliti dalam hal ini dalam melakukan pengamatan terkait fakta sosial kontemporer selanjutnya melakukan penelusuran lewat berita-berita di beberapa media terutama terkait dengan masalah kehidupan perekonomian masyarakat.

Pengolahan dan analisis data dilakukan secara kontinyu sesuai dengan teknik pengolahan dan analisis data kualitatif. Pertama-tama peneliti melakukan pengumpulan data kemudian memilih data yang sesuai dengan yang peneliti kaji, melakukakan pengorganisasian dan menempatkan data dalam penyajian sesuai dengan sistematika selanjutnya menyimpulkan data hasil penelitian yakni terkait solusi dakwah dalam menyikapi problematika ekonomi masyarakat kontemporer.

\section{Hasil dan Pembahasan}

\subsection{Tinjauan tentang Dakwah di Masyarakat}

Dakwah menurut Syekh Ali Mahfudz adalah suatu upaya mendorong atau memotivasi manusia agar melakukan kebaikan dan mengikuti petunjuk serta menyuruh mereka berbuat makruf dan mencegah mereka dari perbuatan mungkar agar mereka memperoleh kebahagiaan dunia dan akhirat (Abdullah, 2015). 


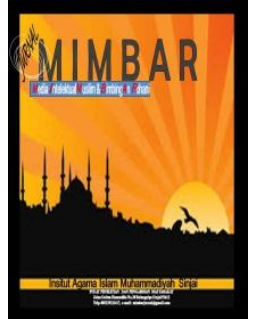

Volume 7, No. 2, 2021

ISSN (print) : 2442-3217 / ISSN (online) : 2716-3806

Email : mimbarjurnal@gmail.com

Homepage : http://journal.iaimsinjai.ac.id/indeks.php/mimbar

DOI : https://doi.org/10.47435/mimbar.v7i2

Kebahagiaan dunia dan akhirat merupakan tujuan yang ditekankan pada defenisi dakwah yang disampaikan oleh Syekh Ali Mahfudz tersebut di atas dan hal tersebut hanya bisa dicapai dengan mengajak, mendorong dan memotivasi umat manusia agar berbuat baik, melaksanakan perbuatan yang makruf dan mencegah mereka berbuat kemungkaran.

Mengajak manusia berbuat makruf dan mencegah berbuat mungkar merupakan esensi dari aktivitas dakwah yang merupakan hal yang tidak mudah, dibutuhkan kompetensi yang cukup untuk efektivitas dari pelaksanaan dakwah tersebut. Hal ini karena kewajiban dakwah merupakan kewajiban dan tugas setiap individu. meskipun pelaksanaannya sebaiknya disesuaikan dengan kemampuan dan kondisi di lapangan.

Kewajiban berdakwah sesungguhnya diamanahkan kepada setiap muslim, mereka wajib melaksanakan dakwah Islamiyah, karena dakwah merupakan tugas 'ubudiyah dan sebagai bukti keikhlasan kepada Allah Swt. Sehingga penyampaian dakwah Islamiyah haruslah disempurnakan dari satu generasi ke generasi berikutnya agar cahaya hidayah Allah Swt. tidak terputus sepanjang masa. Hal ini bermula dari para rasul dan nabi yang merupakan tokoh-tokoh dakwah paling terkemuka dalam sejarah umat manusia, mereka dibekali wahyu dan tuntunan yang sempurna, selanjutnya tugas dan tanggung jawab tersebut diwariskan kepada umatnya dengan mewajibkan mereka untuk mengambil teladan dari Rasulullah (Aminudin, 2018). Terkait dengan tugas dan tanggung jawab dakwah yang diamanahklan kepada setiap umat muslim, maka dakwah memiliki beberapa fungsi dakwah yang dapat dilihat sebagai berikut;

1. Untuk menyebarkan islam kepada manusia sebagai individu dan masyarakat sehingga, meratalah rahmat islam kepada seluruh alam semesta.

2. Untuk melestarikan nilai-nilai Islam dari generasi ke generasi sehingga kelangsungan ajaran Islam beserta pemeluknya tidak putus.

3. Untuk korektif yaitu meluruskan akhlak yang bengkok, mencegah kemungkaran dan mengeluarkan manusia dari kegelapan rohani (Hasan, 2013). 


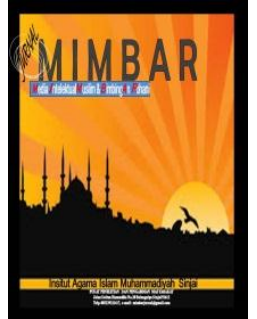

Volume 7, No. 2, 2021

ISSN (print) : 2442-3217 / ISSN (online) : 2716-3806

Email : mimbarjurnal@gmail.com

Homepage : http://journal.iaimsinjai.ac.id/indeks.php/mimbar

DOI

: https://doi.org/10.47435/mimbar.v7i2

Dakwah sebagai metode atau jalan untuk menyebarkan, melestarikan dan mengoreksi akhlak manusia mengindikasikan adanya perubahan yang akan terjadi sebagai efek dari pelaksanaan dakwah. Selain fungsi dakwah, maka perlu juga untuk memahami arah dan tujuan dakwah agar dakwah yang dilakukan benarbenar optimal. Adapun arah dan tujuan dakwah dapat dilihat sebagai berikut:

1. Dar al-salam (peace and harmony area) yaitu dakwah dilkukan sebagai alat atau cara agar manusia hidup damai dan harmonis dalam proses interaksi satu dengan lainnya.

2. Dialog dan menghindari ikrah yakni melakukan dialog dengan memertahankan budaya lama yang baik dan mengambil budaya baru yang lebih baik

3. Integral yakni mempertimbanglan sudur-sudut persoalan dakwah, kemampuan, kapasitas, dan target-target dakwah yang lebih realistik, termasuk dalam hal ini melakukan dakwah secara terorganisir dan manajerial.

4. Pelaksanaan dakwah menjawab tantang dan problem sosial (solutif).

5. Konsep Rahmatan lil'alamin (penebar kasih bagi sekalian alam) bahwa misi Islam tidak bisa disampaikan dengan cara pemaksaan karena bisa menimbulkan perlawanan, kepatuhan buta, dan cenderung pada tindakan zalim (Muhyiddin et al., 2014).

Mencermati fungsi, arah dan tujuan dakwah yang mengehendaki adanya perubahan pada diri mitra dakwah, maka perlu juga dalam hal ini dipahami terkait dengan objek dakwah atau masyarakat dakwah. Masyarakat menurut Ralp Linton dalam Sidi Gazalba dalam Abdul Basit adalah kelompok manusia yang cukup lama hidup dan bekerja sama sehingga dapat mengorganisasikan dirinya dan dapat berpikir mengenai dirinya sebagai suatu kesatuan sosial yang mempunya batasbatas tertentu (Basit, 2013).

\subsection{Tinjauan tentang Dakwah dan Problematika Masyarakat Modern}

Dewasa ini probleamatika hidup masyarakat modern semakin kompleks, Perkembangan zaman tidak dapat dipungkiri membuat masyarakat semakin terjebak pada era globalisasi. Segala aspek kehidupan baik di bidang sosial, 


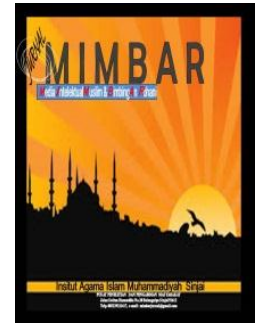

Volume 7, No. 2, 2021

ISSN (print) : 2442-3217 / ISSN (online) : 2716-3806

Email : mimbarjurnal@gmail.com

Homepage : http://journal.iaimsinjai.ac.id/indeks.php/mimbar

DOI : https://doi.org/10.47435/mimbar.v7i2

politik, ekonomi, budaya, maupun di bidang yang lain selalu berbenturan dengan teknologi yang diharapkan dapat meningkatkan mutu kehidupan (Haris, 2018).

Masyarakat modern sebagai kumpulan dari individu atau manusia yang dalam kehidupannya sangat mementingkan pencapaian-pencapaian pribadi daripada kolektif. Di tengah iklim kompetisi yang sangat tinggi, bahkan tidak jarang sangat keras, sikap individualis tampaknya seakan menjadi konsekuensi logis dari sebuah hubungan antar individu (Said, 2013).

Menyikapi problematika umat manusia dewasa, maka peran dakwah sangatlah dibutuhkan sebagai upaya untuk mewujudkan Islam sebagai rahmat bagi semesta alam yang dijelaskan dalam Q.S. AL-Anbiya ayat 107.

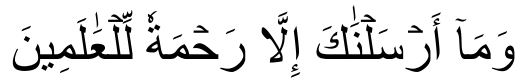

Terjemahnya; Dan tiadalah Kami mengutus kamu, melainkan untuk (menjadi) rahmat bagi semesta alam (Kementerian Agama, 2014). Perwujudan isalm sebagai rahmat bagi seluruh isi alam semesta terutama kepada sesama manusia sangatlah dibutuhkan. Hal ini terkait dengan esensi tugas manusia dalam menjadi Khalīfah $f i$ al-ardh sehingga tidak akan lepas dari berbagai hal yang terkait dengan kehidupan bersosial dan bermasyarakat yang berkaitan dengan akhlak, baik akhlak kepada Tuhan, diri sendiri, keluarga, masyarakat, bangsa dan negara. Demikianlah tugas dan tanggung jawab dakwah sebagai jalan untuk merealisasikan misi Islam sebagai rahmat bagi semesta alam yang sarat dengan tantangan terutama di era globalisasi dan informasi seperti saat ini.

\section{A. Tinjauan Tentang Solusi Dakwah dalam Menyikapi Problematika Ekonomi \\ Masyarakat}

Problematika ekonomi masyarakat dewasa ini sangatlah kompleks, angka kemiskinan masih sangat tinggi dan angka kelaparan akibat kemiskinan juga sangat memprihatinkan. Menurut beberapa pemberitaan diketahui bahwa indeks kemiskinan terjadi secara multidimensi yakni tidak hanya terkait dengan penghasilan tetapi juga mencakup akses air bersih, pendidikan, makanan, listrik dan enam indikator lainnya (Abdila, 2021).

Mencermati kompleksnya problematika kemiskinan yang melanda masyarakat dewasa ini, makan dibutuhkan solusi dari berbagai pihak agar 


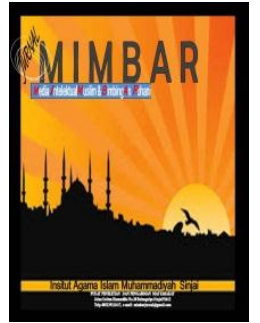

Volume 7, No. 2, 2021

ISSN (print) : 2442-3217 / ISSN (online) : 2716-3806

Email : mimbarjurnal@gmail.com

Homepage : http://journal.iaimsinjai.ac.id/indeks.php/mimbar

DOI

: https://doi.org/10.47435/mimbar.v7i2

kemiskinan bisa teratasi sehingga kesejahteraan masyarakat bisa merata. Oleh karena itu salah satu hal yang perlu untuk diketahui dan dipahami adalah penyebab kemiskinan yang terjadi di masyarakat terutama masyarakat Indonesia. Menurut ilmu sosiologi penyebab kemiskinan adalah faktor psikologis kultural individu seperti rasa malas dan tidak adanya etos kerja serta keinginan berwirausaha, faktor struktural yaitu tidak adanya modal usaha dan kompetisi yang sangat ketat, dan yang terakhir adalah faktor warisan atau keturunan (Zulfikar, 2021).

Beragamnya penyebab kemiskinan yang jika dikategorikan bahwa kemiskinan yang diderita dan dirasakan oleh masyarakat disebabkan oleh dua faktor yaitu faktor internal yakni dari dalam diri penderita dan faktor eksternal yakni yang berasal dari luar penderita. Sehingga dalam penanganannya juga diperlukan solusi atau upaya yang berbeda tergantung dari penyebab yang diderita.

Penyebab kemiskinan karena faktor ekternal membutuhkan bimbingan rohani untuk membangun etos kerja dari penderita. Dai dalam hal ini sebagai agen penyampai dakwah harus memahami tentang kebutuhan individu seperti

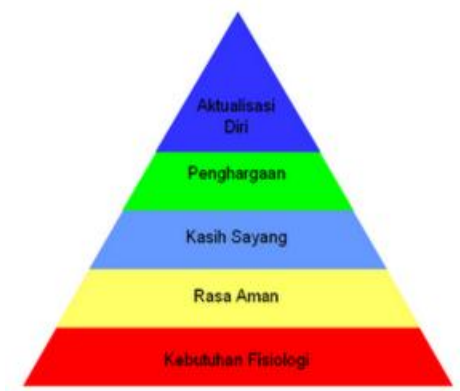

Teopi Kebutuhon Moslow sumber: http://necture.bdyrone.com/ pemahaman terkait teori kebutuhan menurut Abraham Maslow yang menguraikan tentang defenisi ekonomi sebagai salah satu bidang kajian yang berusaha untuk menyelesaikan kebutuhan manusia melalui pembimbingan pada sumber ekonomi dengan berlandaskan pada prinsip serta teori tertentu dalam suatu sistem ekonomi yang dianggap efektif dan efisien, sedangkan (Abdi,

2021) Adapun hierarki kebutuhan menurut Abraham Maslow dapat dilihat pada gambar disamping (Unkris, 2018). Defenisi Ekonomi menurut M.Manullang adalah ilmu yang mempelajari tentang tata cara memenuhi keinginan manusia atau masyarakat demi tercapainya kemakmuran atau kondisi dimana manusia bisa memenuhi kebutuhannya, baik dalam bentuk barang maupun jasa (Abdi, 2021). 


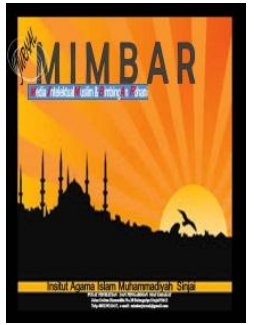

Volume 7, No. 2, 2021

ISSN (print) : 2442-3217 / ISSN (online) : 2716-3806

Email : mimbarjurnal@gmail.com

Homepage : http://journal.iaimsinjai.ac.id/indeks.php/mimbar

DOI $\quad$ : https://doi.org/10.47435/mimbar.v7i2

Defenisi dan dan hierarki kebutuhan manusia tersebut mengindikasikan bahwa dalam pemenuhan kebutuhan dan pengentasan kemiskinan membutuhkan kerjasamas dari berbagai elemen masyarakat termasuk dalam hal ini peran dakwah juga sangat dibutuhkan. Islam dalam ajarannya memberikan penjelasan bahwa keberadaan makhluk dan khalik menunjukkan bahwa Islam bukan sekedar agama, melainkan keterpaduan antara agama dan dunia, ibadah dan muamalah, aqidah dan syariah, sehingga kajian-kajian ekonomi tidak dibatasi pada sudut agama tetapi lebih ditekankan pada sudut pandang Islam. Islam memberikan kesempatan yang luas dalam memakmurkan bumi dan meningkatkan kesejahteraan manusia. Hal ini berkaitan bahwa manusia adalah wakil Tuhan demikian juga dengan penciptaan alam dan seluruh isinya untuk kepentingan manusia (Nadjib, 2013). Penjelasan terkait hal ini dapat dilihat dalam QS Ibrahim/ $14: 32$;

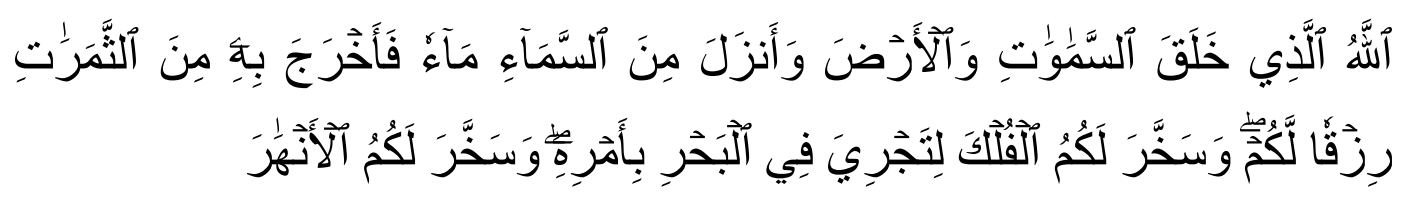

Terjemahnya:

Allah-lah yang telah menciptakan langit dan bumi dan menurunkan air hujan dari langit, kemudian Dia mengeluarkan dengan air hujan itu berbagai buah-buahan menjadi rezeki untukmu; dan Dia telah menundukkan bahtera bagimu supaya bahtera itu, berlayar di lautan dengan kehendak-Nya, dan Dia telah menundukkan (pula) bagimu sungai-sungai.(Kementerian Agama, 2014)

Selanjutnya dalam ayat lain ditemukan bahwa doktrin dalam Islam bahwa

bekerja merupakan ibadah yang berimplikasi pada banyak hal. Dengan bekerja manusia dapat melanjutkan kehidupan dalam menjalankan amanat Tuhannya, menjaga dirinya serta dapat merealisasikan tujuan-tujuan yang lebih besar, (QS Taubah/9:105);

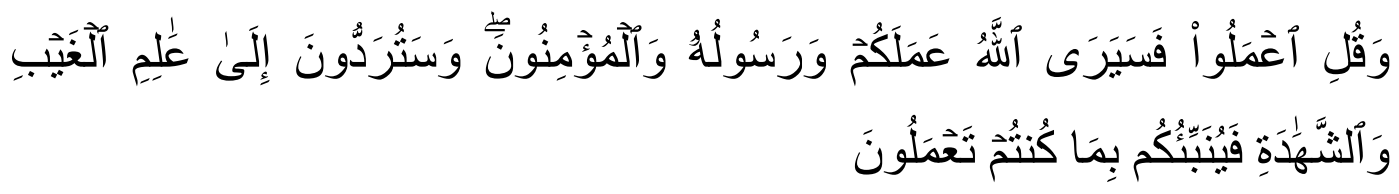

Terjemahnya;

Dan Katakanlah: "Bekerjalah kamu, maka Allah dan Rasul-Nya serta orangorang mukmin akan melihat pekerjaanmu itu, dan kamu akan dikembalikan kepada (Allah) Yang Mengetahui akan yang ghaib dan yang nyata, lalu 


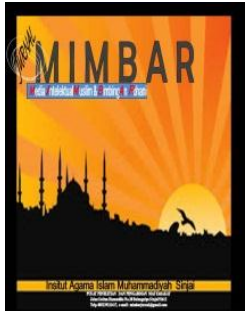

Volume 7, No. 2, 2021

ISSN (print) : 2442-3217 / ISSN (online) : 2716-3806

Email : mimbarjurnal@gmail.com

Homepage : http://journal.iaimsinjai.ac.id/indeks.php/mimbar

DOI $\quad:$ https://doi.org/10.47435/mimbar.v7i2

diberitakan-Nya kepada kamu apa yang telah kamu kerjakan (Kementerian Agama, 2014).

Ayat ini sangat jelas memberikan perintah kepada umat manusia untuk bekerja dan tindakan mereka dalam memenuhi kebutuhannya, keluarga dan masyarakat merupakan tindakan yang sangat terpuji. Setiap usaha yang mereka lakukan akan mendapatkan imbalan berupa karunia (rizqi) di dunia dan berlaku untuk seluruh makhluk hidup dan mereka akan mendapat ganjaran pahala di akhirat. Hal ini dapat kita lihat penjelasannya dala al-Qur'an salah satunya adalah QS Hud/ 11: 6, 11;

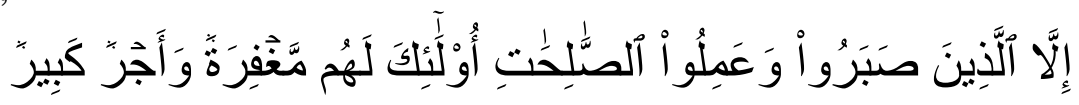

Terjemahnya adalah kecuali orang-orang yang sabar (terhadap bencana), dan mengerjakan amal-amal saleh; mereka itu beroleh ampunan dan pahala yang besar (Kementerian Agama, 2014). Sehingga di sini dapat dilihat konsep ganjaran atau reward yang akan diberikan oleh Allah swt kepada manusia yang bekerja dan bersabar atas pekerjaan yang ditekuninya. Selain ayat dalam al-Qur'an, perintah bekerja juga dijelaskan dalam hadis di antaranya adalah hadis yang diriwayatkan oleh Abu Hurairah, Rasulullah SAW bersabda:

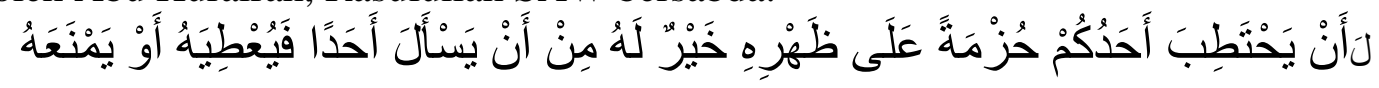

Artinya: Sungguh seorang dari kalian yang memanggul kayu bakar dengan punggungnya lebih baik baginya daripada dia meminta-minta kepada seseorang, baik orang itu memberinya atau menolaknya. (HR al-Bukhari dan Muslim) (Nadjib, 2013). Hadis ini sangat jelas memerintahkan untuk bekerja dan mencela orang yang meminta-minta. Sehingga sangat jelas dipahami bahwa Islam sebagai salah satu agama di dunia dalam lingkup yang luas dan di Indonesia dalam lingkup yang khusus sangat menganjurkan pemeluknya untuk bekerja dan menghindari meminta-minta.

Selain terkait anjuran bekerja, dalam Islam juga diatur penggunaan waktu yang merupakan salah satu elemen yang berperan penting dalam aspek kehidupan terutama dalam hal pekerjaan. Kehidupan muslim yang baik sangat identik dengan keteraturan penggunaan waktu, baik untuk menjalankan aspek ibadah maupun untuk bekerja. Secara mendasar, Al-Qur'an menentang tindakan malas, 


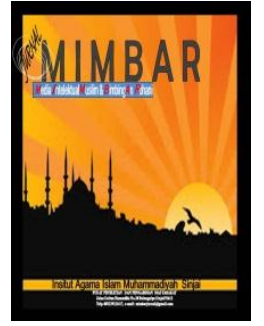

Volume 7, No. 2, 2021

ISSN (print) : 2442-3217 / ISSN (online) : 2716-3806

Email : mimbarjurnal@gmail.com

Homepage : http://journal.iaimsinjai.ac.id/indeks.php/mimbar

DOI : https://doi.org/10.47435/mimbar.v7i2

menyia-nyiakan waktu dan melakukan hal-hal yang tidak produktif,.. (QS Al'Asr 103:1-3;

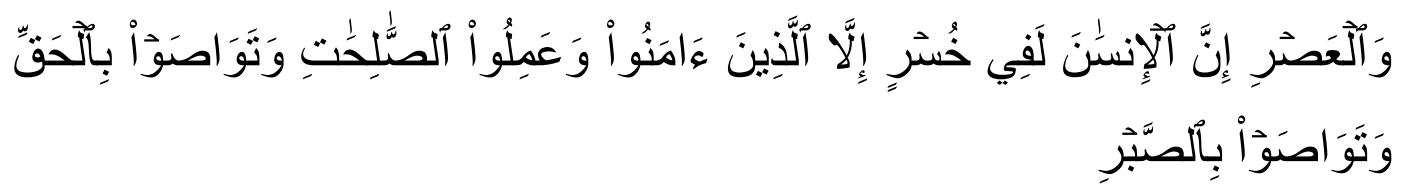

Terjemahnya; Demi masa, sesungguhnya manusia itu benar-benar dalam kerugian,, kecuali orang-orang yang beriman dan mengerjakan amal saleh dan nasehat menasehati supaya mentaati kebenaran dan nasehat menasehati supaya menetapi kesabaran (Kementerian Agama, 2014). Di antara banyak hal yang diajarkan dan diperintahkan oleh Allah swt dalam ayat ini adalah perintah untuk disiplin dan menggunakan waktu dengan baik.

Konsep etos kerja dan kedisiplinan yang merupakan faktor yang sangat berperan dalam peningkatan kualitas hidup masyarakat, hal lain yang dapat menjadi pemantik etod kerja masyarakat muslim adalah perintah dalam rukun Islam tentang kewajiban berzakat dan naik haji, kewajiban ini tentunya mengisyaratkan kemampuan finansial atau berkaitan dengan materi. Di samping itu terdapat juga ayat dalam Al-Qur'an yang menegaskan bahwa Allah swt tidak akan mengubah nasib suatu kaum kalau bukan dia sendiri yang mengubahnya, (QS. Ar-Ra'd Ayat 11).

Di samping perintah untuk bekerja, meningkatkan etos kerja dan memanfaatkan waktu semaksimal mungkin, di dalam ajaran Islam juga diperintahkan untuk bersedekah dan berzakat, hal ini mengindikasikan kebutuhan akan kepekaan sosial, empati dan simpati terhadap kondisi yang terjadi di sekitar. Seorang yang mendapatkan rezeki sebaiknya berbagi dengan masyarakat sekitarnya menciptakan lapangan kerja dan memberika modal usaha.

Pembagian zakat dan sedekah memerlukan wadah yang amanah sehingga optimalisasi peran badan amil zakat dan pemerintah sangat dibutuhkan dalam hal tersebut. Dakwah dalam hal ini berperan untuk menyadarkan dan meningkatkan pemahaman umat muslim untuk berbagi kepada sesama, mendata masyarakat

\footnotetext{
${ }^{1}$ file:///C:/Users/ME/Downloads/358-309-1-PB\%20(1).pdf,
} 


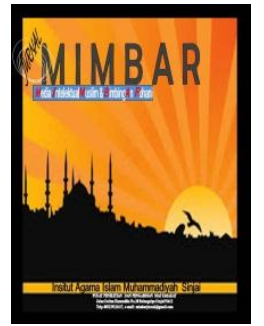

Volume 7, No. 2, 2021

ISSN (print) : 2442-3217 / ISSN (online) : 2716-3806

Email : mimbarjurnal@gmail.com

Homepage : http://journal.iaimsinjai.ac.id/indeks.php/mimbar

DOI : https://doi.org/10.47435/mimbar.v7i2

yang butuh disantuni dan mendistribusikan zakat dan sedekah kepada yang benarbenar membutuhkan.

Selain kebutuhan kepekaan atau kecerdasan sosial, dalam pengentasan kemiskinan juga dibutuhkan peningkatan kualitas manusia melalui jalur pendidikan, hal ini juga sejalan dengan perintah Allah swt dalam Q.S. AlMujadalah Ayat 11 bahwa orang yang berpendidikan dan bertakwa akan diangkat derajatnya oleh Allah swt.

Prof Bagong, Dekan FISIP Unair mengungkapkan bahwa salah satu penyebab sulitnya memutus rantai kemiskinan dikarenakan oleh faktor struktural yang tidak ramah dan kebijakan pemerintah yang bersifat meritokrasi yakni belum berpihak untuk melindungi si miskin. Menurutnya Kebijakan meritokrasi adalah pemberian bantuan kepada hanya agar mereka bertahan hidup (Zulfikar, 2021).

Ketua Dewan Masjid Indonesia (DMI), Jusuf Kalla, menyerukan umat Muslim untuk hijrah. Hijrah yang dimaksud Jusuf Kalla adalah meningkatkan partisipasi umat Islam dalam pembenahan dan perbaikan ekonomi Tanah Air. Dengan cara itu ekonomi Indonesia diyakini Jusuf Kalla dapat membaik. Imbasnya, tentu ke penguatan ekonomi umat Islam. Jusuf Kalla menyatakan bahwa "kalau ekonomi nasional sejahtera, tentu 99 persen, umat juga sejahtera. ${ }^{2}$

Pendapat senada juga disampaikan bahwa Kemandirian ekonomi negara Muslim adalah hal yang seharusnya dijadikan hal penting. Meski saat ini kondisi perekonomian hampir disemua negara Muslim dalam kondisi memprihatinkan, namun basis-basis bagi kemandirian itu harus ditanamkan dengan kokoh. Selain iptek yang tak kalah penting adalah pertanian mengarah pada swasembada, kemudian usaha-usaha bagi pemenuhan kebutuhan primer masyarakat (Ramdhani, 2013).

Mencermati problematika ekonomi masyarakat yang sangat kompleks dewasa dan dikaitkan dengan beberapa perintah dalam Al-Qur'an, maka dapat dikatakan bahwa beberapa upaya yang dapat dilakukan dalam mengentaskan

2 https://voi.id/bernas/59407/benarkah-umat-islam-cenderung-miskin-seperti-dikatakanjusuf-kalla-jika-benar-kenapa, di akses 27 Oktober 2021. 


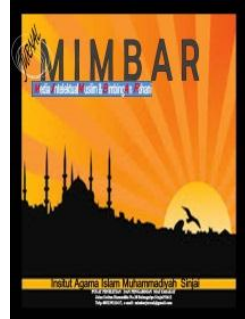

Volume 7, No. 2, 2021

ISSN (print) : 2442-3217 / ISSN (online) : 2716-3806

Email : mimbarjurnal@gmail.com

Homepage : http://journal.iaimsinjai.ac.id/indeks.php/mimbar

DOI $\quad:$ https://doi.org/10.47435/mimbar.v7i2

kemiskinan multidimensi adalah dengan menggunakan pendekatan keagamaan, struktural, dakwah, psikologi, Pendidikan, ekonomi dan sosial.

\section{Simpulan}

Solusi dakwah dalam menyikapi problematika ekonomi masyarakat adalah dengan memahami penyebab terjadinya kemiskinan sehingga solusi yang diberikan sesuai dengan sumber permasalahan yang ada. Adapun problematika ekonomi masyarakat dewasa ini yang sangat kompleks jika dikaitkan dengan beberapa perintah dalam Al-Qur'an, maka dapat dikatakan bahwa beberapa upaya yang dapat dilakukan dalam mengentaskan kemiskinan multidimensi adalah dengan menggunakan pendekatan keagamaan, struktural, dakwah, psikologi, Pendidikan, ekonomi dan sosial

\section{Daftar Pustaka}

Abdi, H. (2021). Pengertian Ekonomi Menurut Para Ahli dan Prinsipnya yang Perlu Dipahami. Hot.Liputan6.Com. https://hot.liputan6.com/read/4580554/pengertian-ekonomi-menurut-paraahli-dan-prinsipnya-yang-perlu-dipahami

Abdila, R. (2021). Angka Kemiskinan Indonesia Meningkat Akibat Pandemi Covid-19. Tribunnews.Com.

https://www.tribunnews.com/bisnis/2021/10/09/angka-kemiskinanindonesia-meningkat-akibat-pandemi-covid-19

Abdullah, A. (2015). Ilmu dakwah: kajian ontologi, epistemologi, aksiologi dan aplikasi dakwah. Citapustaka media Perintis.

Aminudin, A. (2018). DAKWAH DAN PROBLEMATIKANYA DALAM MASYARAKAT MODERN. Al-MUNZIR, 8(1), 15-29.

Basit, A. (2013). Filsafat Dakwah. Rajagrafindo Persada.

Fauzie, Y. Y. (2021). Ironi, Merdeka di Atas 27 Juta "Perut Lapar." Cnnindonesia.Com. https://www.cnnindonesia.com/ekonomi/20210811103736-532679086/ironi-merdeka-di-atas-27-juta-perut-lapar

Haris, M. (2018). Urgensi Dakwah dan Problematika Masyarakat Global. Tasamuh: Jurnal Studi Islam, 10(1), 1-29.

Hasan, M. (2013). Metodologi Pengembangan Ilmu Dakwah. Pena Salsabila.

Indonesia, C. (2021). Angka Kemiskinan di Indonesia Naik, Hingga Uang Euro Digital. Cnbcindonesia.Com. https://www.cnbcindonesia.com/news/20210715183323-8-261278/angkakemiskinan-di-indonesia-naik-hingga-uang-euro-digital

Kementerian Agama, R. I. (2014). Al-Quran dan Terjemahnya. Jakarta: PT. Hati Emas.

Martono, N. (2012). Sosiologi perubahan sosial: Perspektif klasik, modern, posmodern, dan poskolonial. RajaGrafindo Persada.

Muhyiddin, A., Muhtadi, A. S., Hamad, I., Mufid, A. S., Sambas, S., Sarbini, A., Solahudin, D., Sukayat, T., Aripudin, A., \& Saepullah, U. (2014). Kajian dakwah multiperspektif teori, metodologi, problem dan aplikasi. Remaja 


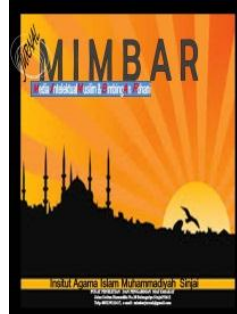

\section{MIMBAR}

Volume 7, No. 2, 2021

ISSN (print) : 2442-3217 / ISSN (online) : 2716-3806

Email : mimbarjurnal@gmail.com

Homepage : http://journal.iaimsinjai.ac.id/indeks.php/mimbar

Rosdakarya.

DOI $\quad:$ https://doi.org/10.47435/mimbar.v7i2

Nadjib, M. (2013). Agama, Etika dan Etos Kerja dalam Aktivitas Ekonomi Masyarakat Nelayan Jawa. Jurnal Ekonomi Dan Pembangunan, 21(2), 137150.

Ramdhani, R. (2013). Problematika Dakwah Di Dunia Islam Dan Solusi Filosofisnya. Syi'ar, 13(2).

Said, N. M. (2013). Dakwah dan Problematika Umat Islam. Jurnal Dakwah Tabligh, 14(1), 1-23.

Tim PRMN 03. (2020). Bukan karena Covid-19, 30 Juta Orang di Dunia Justru Berisiko Meninggal akibat Kelaparan. Pikiran-Rakyat.Com.

https://www.pikiran-rakyat.com/internasional/pr-01753612/bukan-karenacovid-19-30-juta-orang-di-dunia-justru-berisiko-meninggal-akibat-kelaparan

Unkris. (2018). Teori hierarki kebutuhan Maslow. P2k.Unkris.Ac.Id. http://p2k.unkris.ac.id/id3/1-3065-2962/Teori-Hierarki-KebutuhanMaslow_146129_p2k-unkris.html

Zulfikar, F. (2021). "Ternyata Penyebab Miskin Bukan karena Malas Bekerja, Ini Penjelasan Pakar Unair. Detik.Com.

https://www.detik.com/edu/detikpedia/d-5787074/ternyata-penyebab-miskinbukan-karena-malas-bekerja-ini-penjelasan-pakar-unair 